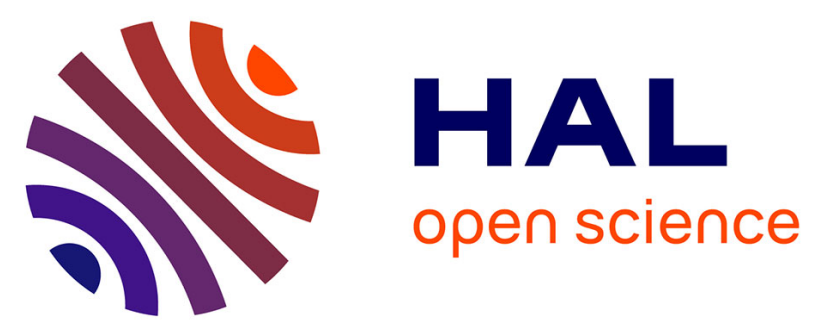

\title{
First temperature database achieved with Fiber Bragg Grating sensors in uncooled plasma facing components of the WEST lower divertor
}

Y Corre, N Chanet, Romain Cotillard, J Gaspar, Guillaume Laffont, C Pocheau, G Caulier, C Destouche, J-L Gardarein, M Firdaouss, et al.

\section{To cite this version:}

Y Corre, N Chanet, Romain Cotillard, J Gaspar, Guillaume Laffont, et al.. First temperature database achieved with Fiber Bragg Grating sensors in uncooled plasma facing components of the WEST lower divertor. Fusion Engineering and Design, 2021, 170, pp.112528. 10.1016/j.fusengdes.2021.112528 . hal-03583708

\section{HAL Id: hal-03583708 \\ https://hal-amu.archives-ouvertes.fr/hal-03583708}

Submitted on 22 Feb 2022

HAL is a multi-disciplinary open access archive for the deposit and dissemination of scientific research documents, whether they are published or not. The documents may come from teaching and research institutions in France or abroad, or from public or private research centers.
L'archive ouverte pluridisciplinaire HAL, est destinée au dépôt et à la diffusion de documents scientifiques de niveau recherche, publiés ou non, émanant des établissements d'enseignement et de recherche français ou étrangers, des laboratoires publics ou privés.

\section{(1) (1) $\$$}

Distributed under a Creative Commons Attribution - NonCommercial - NoDerivatives 44.0 


\title{
First temperature database achieved with Fiber Bragg Grating sensors in uncooled plasma facing components of the WEST lower divertor
}

\author{
Y. Corre ${ }^{\mathrm{a}}$, N. Chanet ${ }^{\mathrm{a}}$, R. Cotillard ${ }^{\mathrm{b}}$, J. Gaspar ${ }^{\mathrm{c}}$, G. Laffont ${ }^{\mathrm{b}}$, C. Pocheau ${ }^{\mathrm{a}}$, G. Caulier ${ }^{\mathrm{a}}$, C. \\ Destouche $^{\mathrm{d}}$, J-L. Gardarein ${ }^{\mathrm{c}}$, M. Firdaouss ${ }^{\mathrm{a}}$, M. Houry ${ }^{\mathrm{a}}$, M. Missirlianª ${ }^{\mathrm{a}}$, N. Roussel ${ }^{\mathrm{b}}$, B. \\ Santraine $^{\mathrm{a}}$ and the WEST team \\ ${ }^{a}$ CEA, IRFM, F-13108 Saint-Paul-lez-Durance, France. \\ ${ }^{b}$ CEA, List, Gif-sur-Yvettes cedex, 91191, France \\ ${ }^{c}$ Aix-Marseille Université, CNRS, IUSTI UMR 7343, 13013 Marseille, France \\ ${ }^{d}$ CEA, DES, IRESNE, DER, SPESI Cadarache F-13108 Saint-Paul-Lez-Durance, France \\ * See http://west.cea.fr/WESTteam
}

\begin{abstract}
Plasma Facing Components (PFCs) temperature measurement is required to ensure safe high power for long pulse tokamak operation and for physics studies. A set of twenty thermocouples (TCs) and four optical fiber temperature sensing probes, each of them including eleven wavelengthmultiplexed fiber Bragg gratings (FBGs) written with UV radiation, have been integrated and deployed in the WEST lower divertor. To avoid any thermal erasure occurring above $400^{\circ} \mathrm{C}$, the gratings have been regenerated using a high temperature annealing process. The FBG probes are embedded in tungsten-coated graphite components with no active cooling. The diagnostic was working correctly from the first plasma breakdown achieved in WEST (in 2017) until the first dismantling of the lower divertor three years later (2020). Collected data are sorted by temperature range to investigate the ageing of both PFCs and diagnostics. Measurements obtained with FBGs and TCs are consistent, no long-term drift is reported during the overall period of use. The maximum temperature reported by FBGs in the divertor is $830{ }^{\circ} \mathrm{C}$ obtained with $90 \mathrm{MJ}$ of cumulated plasma energy in one pulse. A short but reversible collapse of the Bragg peak (from 5 down to $2 \mathrm{~dB}$ ) has been observed under high temperature due to the strong temperature gradients measured along the fiber (about $20^{\circ} \mathrm{C} / \mathrm{mm}$, for an $\mathrm{FBG}$ size of $3 \mathrm{~mm}$ ). This feedback demonstrates that regenerated FBGs are suitable for long-term temperature monitoring in tokamak environment with high heat load, high temperature and gradient, strong magnetic field and vacuum constraint.
\end{abstract}

Keywords: Regenerated Fiber Bragg grating, optical fiber sensors, high temperature measurement, plasma heat load Corresponding author address: CEA, IRFM, F-13108 Saint-Paul-lez-Durance, France.

Corresponding author e-mail: yann.corre@cea.fr 


\section{Introduction}

The WEST project (W-tungsten Environment and Steady State Tokamak) consists in transforming the Tore Supra tokamak in an X-point divertor configuration while keeping its long pulse capability, in order to test the ITER divertor technology [1]. The main goal is to test the actively cooled tungsten (W) Plasma Facing Units (PFUs) representative of the ITER divertor target [2] under high heat load (in the 10-20 MW.m ${ }^{-2}$ range). In WEST, each PFU is composed of $35 \mathrm{~W}$ monoblocks of individual size $12 \mathrm{~mm} \times 26 \mathrm{~mm}$ (depth $\times$ height), toroidal width varying from 28 to $32 \mathrm{~mm}$ on the high and low field side respectively, assembled with a gap of $0.5 \mathrm{~mm}$ on a CuCrZr heat sink tube [2]. As the completion of the ITER-like target required more time than the tokamak platform, WEST (phase 1) started the operation in 2017 with 6 actively cooled ITER-like PFUs and 450 non-actively cooled PFUs made of graphite with a thin coating of tungsten $(\sim 15 \mu \mathrm{m})$ in the lower divertor. This was the opportunity to test the Fiber Bragg grating (FBG) technology in tokamak environment [3], featuring high temperature as expected in the lower divertor with uncooled components. A FBG consists of a spatially periodic modulation of the refractive index created along a desired length of the core of an optical fiber. A narrow spectral band of the incident light within the fiber is reflected by successive, coherent scattering from the periodic index modulation [4]. The strongest interaction or mode coupling occurs at the Bragg wavelength given by:

$$
\lambda_{B}=2 n_{e} \Lambda
$$

where $n_{e}$ is the effective index of refraction $(\sim 1.46)$ and $\Lambda$ is the grating period. The principle of the temperature measurement is based on the determination of the wavelength shift of the Bragg peak reflected by the grating that is induced by the changes of the grating period and by the thermooptic coefficient of the fiber. FBGs are of great interest for fusion experiment because they are immune to electromagnetic interferences and allow the measurement of a large number of temperature spots along a single fiber. The main limitation is the erasure of the gratings which may occur above $400{ }^{\circ} \mathrm{C}$ for long term operation. FBG high temperature measurement is a challenging task and currently a major research topic. FBG strain or temperature sensors are foreseen in ITER tokamak in the magnet structure (temperature between $4.5 \mathrm{~K}$ and 300K) [5], in the helium cooled lithium lead Test Blanket Module [6] and also in the vacuum vessel [7]. They have been already tested and installed in the Joint European Torus (JET) [8] and ASDEX Upgrade (AUG) [9] tokamaks to measure forces induced on the vacuum vessel during disruption and deformation of the passive stabilizing loop induced during plasma experiment respectively. More recently, FBG

have been successfully used to monitor the temperature of a W/ Cu mono-block mock-up based on the ITER technology during a high heat flux (HHF) test up to $10 \mathrm{MW} \cdot \mathrm{m}^{-2}$ heat load $[10,11]$. Among the various solutions considered to develop temperature-resistant FBGs, the regeneration process [12] shows that the FBG can survive above $900^{\circ} \mathrm{C}$ with long-term use (> 9000 hours). 
The FBG diagnostic has worked correctly from the first plasma breakdown achieved in WEST, measuring the first plasma quivering, until the dismantling of the lower divertor three years later. This paper reports on temperature measurements achieved over that period, covering more than 2600 pulses with continuous increase in plasma performances and power capabilities, as well as technological limitation arising at high temperature and long-term stability of FBG measurements in a tokamak environment.

The paper is organized as follows. The experimental set-up and temperature measurements data-base are presented in section 2. Section 3 shows the record achieved in WEST in term of temperature as well as the dynamic of the spectrum under very high temperature gradient. A strong collapse of the Bragg peak was observed. The last section shows the ageing of the FBG diagnostic after 3 years of exploitation.

\section{Experimental set-up and temperature measurement database}

\section{1) Diagnostic set-up}

The goal of the FBG diagnostic in WEST is to monitor the bulk temperature in order to: (1) protect the component and its coating to avoid any excessive thermal dilatation and cracks formation [13], (2) cross-calibrate the IR thermography system which is disturbed by the emissivity uncertainties and potential reflection in the hot environment [14], (3) compute the plasma heat load as depicted in [15] and last (4) test the feasibility to use an FBG system directly into the PFU. Four optical fiber temperature sensing probes, each of them including eleven regenerated fiber Bragg gratings equally spaced by $12.5 \mathrm{~mm}$ (equivalent to one ITER-like tungsten monoblock), have been specifically designed and manufactured for the WEST project (full description of the first FBG diagnostic is given in [3]). The four probes are embedded in W-coated graphite components at two different distances from the surface, center of the grooves are $4 \mathrm{~mm}$ (FBG upper) and $7.5 \mathrm{~mm}$ (FBG lower) to cover a wide range of temperature. In the WEST lower divertor, each individual graphite PFU is divided into two parts, the High Field Side (HFS) and Low Field Side (LFS) PFU. The size of the W-coated graphite PFU is about $30 \mathrm{~mm}$ large, $26 \mathrm{~mm}$ thick (height), $326 \mathrm{~mm}$ and $256 \mathrm{~mm}$ long for the HFS and LFS PFU respectively. The FBG diagnostic is installed in the LFS of the divertor, below the outer strike point (OSP), because the heat load is expected to be higher on this part (see figure 1). 


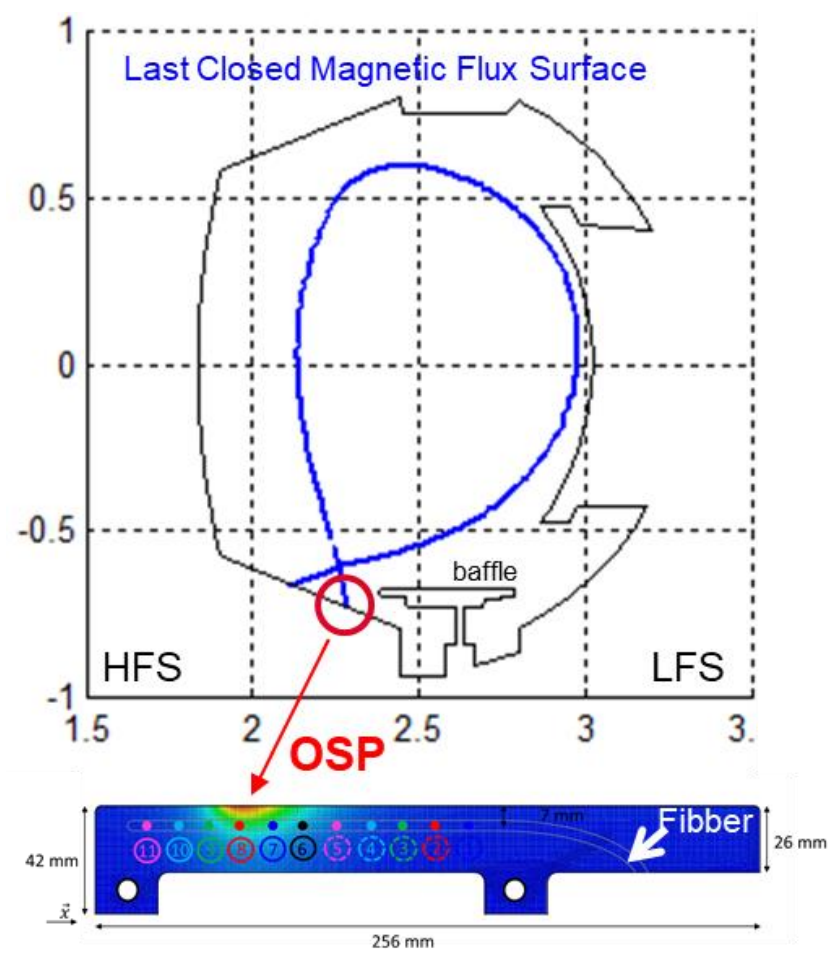

Figure 1: Lower single null magnetic configuration with fixed toroidal magnetic field $\mathrm{B}=3.7$ $\mathrm{T}$ at $\mathrm{R}_{0}=2.5 \mathrm{~m}$. The FBG probes are located below the OSP.

The deployment of the FBG system in WEST is based on one set of two optical fibers, upper and lower FBG which are installed in two adjacent PFU, duplicated in two different divertor sectors (each sector having $30^{\circ}$ toroidal extension). The FBG sensors are located in the maximum heat load areas regarding the toroidal modulation of the magnetic field (see figure 2). The material used is graphite R6710 delivered by SGL carbon company (with thermal conductivity of $\mathrm{K} \sim 82 \mathrm{~W} . \mathrm{m}^{-}$ ${ }^{1} . \mathrm{K}^{-1}$ at $\mathrm{T}=200^{\circ} \mathrm{C}$ ) and the $\mathrm{W}$-coating is about $15 \mu \mathrm{m}$ thick. Surface temperature should be limited to $1200^{\circ} \mathrm{C}$ for standard operation and further (up to $1800^{\circ} \mathrm{C}$ ) for a limited number of experiments to avoid delamination of the $\mathrm{W}$-coating [13]. 


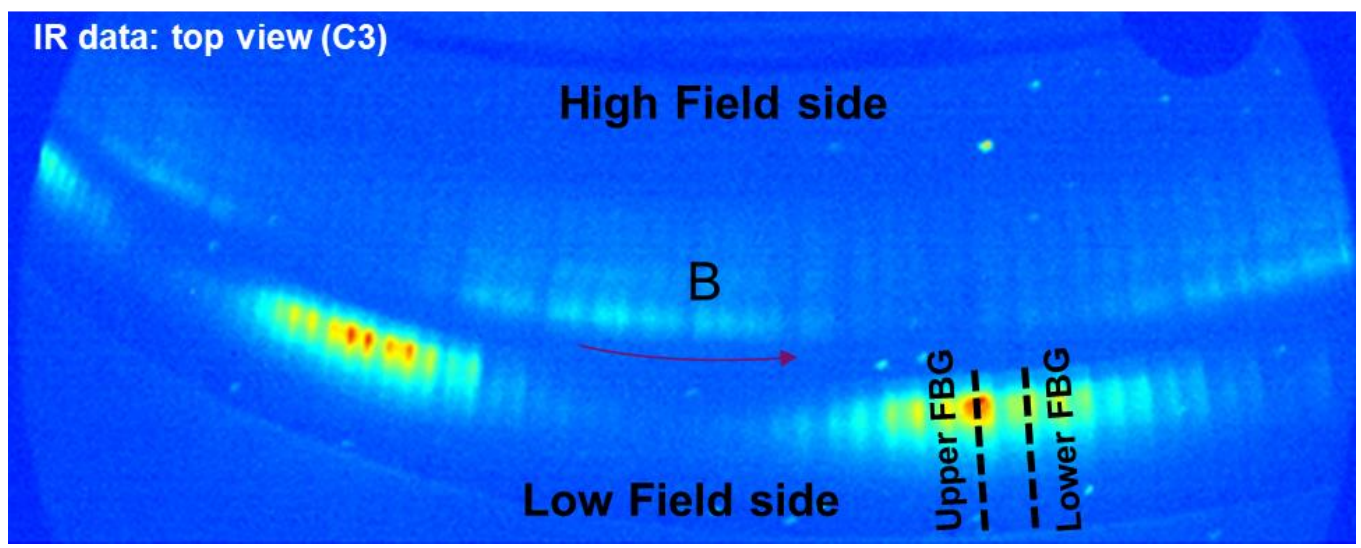

Figure 2: Infrared (IR) image of the lower divertor equipped with W-coated graphite PFUs. Upper and lower FBG are located on the maximum heat load areas.

The typical size of a single fiber Bragg grating is about $3 \mathrm{~mm}$ in length and space between two consecutive FBGs is $12.5 \mathrm{~mm}$. The eleven $12.5 \mathrm{~mm}$ spaced FBGs are simultaneously regenerated using a high-temperature annealing process as depicted in [16]. The process is performed with a homemade compact tubular furnace and uses a thermocouple near the FBG in order to control the temperature during the thermal treatment. During the regeneration protocol, the temperature of the furnace is raised to $920^{\circ} \mathrm{C}$ which is the point triggering the regeneration for all the multiplexed FBGs. The full process, FBG photowriting using a UV cw argon laser emitting at $244 \mathrm{~nm}$ followed by the regeneration step, has been applied successfully to the four dedicated temperature probes. The probes are made of $150 \mu \mathrm{m}$ diameter single-mode polyimide-coated silica-glass optical fiber inserted within a $1 \mathrm{~mm}$ diameter metallic capillary hermetically sealed at its extremity. The temperature probe is fixed to the component with graphite adhesive made for use up to $1300^{\circ} \mathrm{C}$. The thermal behavior of the W-coated graphite PFU is simulated with finite-element calculation performed with the ANSYS [13] or CASTEM codes [15]. A 2D nonlinear unsteady calculation combined with the Conjugate Gradient Method (CGM) and the adjoint state is used in order to estimate the space and time evolution of the surface heat flux, $\mathrm{q}_{\mathrm{n}}\left[\mathrm{MW} \cdot \mathrm{m}^{-2}\right]$, based on FBG or TC temperature measurements $[15,17]$.

\section{2) WEST experiments (Phase 1)}

WEST is currently equipped with upper and lower divertor coils, W-coated upper divertor, baffle, inner bumper and with a flexible lower divertor made of twelve $30^{\circ}$ sectors where the $\mathrm{W}$-coated and ITER-like $\mathrm{W}$ monoblocks are installed. The additional heating and current drive power is provided by high frequency heating systems, namely ion cyclotron resonance heating (ICRH) and lower hybrid current drive (LHCD), capable to deliver up to $9 \mathrm{MW}$ of ICRH power and $7 \mathrm{MW}$ of LHCD power. The WEST magnetic configurations allow for elongated plasmas in lower or upper single null, or double null configurations. For a standard elongated lower single null case, the X- 
point height range, is up to $10 \mathrm{~cm}$, see figure 1 . In its first phase of operation with a mix of actively cooled and non-actively cooled components, WEST has achieved four experimental campaigns, from $\mathrm{C} 1$ to $\mathrm{C} 4$. The first one was dedicated to the commissioning of the machine and plasma breakdown strategy (C1) [18]. The second one was dedicated to the increase of the plasma current, development of the X-point magnetic configuration and increase of the external power (C2). The last two experimental campaigns were dedicated to physics studies and performances improvement (C3 and C4). The main achievements performed in WEST Phase I are summarized in table 1. WEST had cumulated about 6 hours of plasma exposure and 17 GJ of injected energy. The main scenario was lower X-point configuration, L-mode operation with divertor peak heat flux up to $\sim 5$ $\mathrm{MW} / \mathrm{m}^{2}$. About 2600 plasma experiments have been successfully achieved. On top of that, a large number of transients (mainly disruptions and MHD events) was also reported ( 2000 transients), each producing thermo-mechanical stresses into the plasma facing components.

\begin{tabular}{|c|c|c|c|c|c|c|c|c|c|c|c|}
\hline & $\begin{array}{c}\mathrm{Nb} \\
\text { Plasma }\end{array}$ & $\begin{array}{l}\text { Ip max } \\
(\mathrm{kA})\end{array}$ & $\begin{array}{c}\text { Duration } \\
\max (\mathrm{s})\end{array}$ & $\begin{array}{c}\text { Cumul } \\
\text { (s) }\end{array}$ & $\begin{array}{l}\text { Disrup- } \\
\text { tions }\end{array}$ & $\begin{array}{c}\mathrm{LH} \\
\text { (pulse) }\end{array}$ & $\begin{array}{c}\text { LH max } \\
(\mathrm{MW})\end{array}$ & $\begin{array}{c}\text { W LH } \\
\text { total (MJ) }\end{array}$ & $\begin{array}{c}\text { IC } \\
\text { (pulse) }\end{array}$ & $\begin{array}{l}\text { IC max } \\
(\mathrm{MW})\end{array}$ & $\begin{array}{l}\text { W IC } \\
\text { total } \\
\text { (MJ) }\end{array}$ \\
\hline $\begin{array}{c}\text { C2 } \\
\text { Nov17-Feb18 }\end{array}$ & 716 & 805 & 10.5 & 1553 & 282 & 168 & 2.5 & 95.5 & 0 & 0 & 0 \\
\hline $\begin{array}{c}\text { C3 } \\
\text { July-Dec18 }\end{array}$ & 1076 & 818 & 37.5 & 7302 & 730 & 572 & 5.3 & 4947 & 186 & 1.4 & 105 \\
\hline $\begin{array}{c}\text { C4 - D2 } \\
\text { July-Nov19 }\end{array}$ & 1157 & 1004 & 55 & 9968 & 755 & 509 & 5.4 & 7823 & 339 & 5.7 & 1139 \\
\hline $\begin{array}{c}\text { C4 - He } \\
\text { Oct-Nov19 }\end{array}$ & 345 & 709 & 29 & 2991 & 275 & 196 & 4.5 & 4300 & 21 & 0.3 & 3 \\
\hline
\end{tabular}

Table 1: Summary of the main achievements performed in WEST phase I: number of plasma, plasma current $\left(\mathrm{I}_{\mathrm{p}}\right)$, maximum pulse duration, cumulated plasma duration, number of disurptions, number of pulses with LH/IC heating, maximum LH/IC heating power, total energy injected with LH/IC systems.

\section{3) FBG measurement}

For each pulse and each FBG sensor, data processing enables to get the position of the peak in the spectrum and the temperature of the component as function of time [17]. Data are synchronized with the WEST clock and recorded from the starting of the pulse up to the end of the plasma phase, with 100s more extension to access the cooling of the PFU. FBG spectrum, peak positions and temperature data are accessible by every-one in the WEST data-base. During each pulse, the temperature of the PFU is rising up to a maximum when the power switch-off, then the accumulated heat diffuses slowly through the components and the temperature of the component drops as illustrated in figure 3 . The initial and maximum of temperature measured by the lower FBG during this pulse are $130^{\circ} \mathrm{C}$ (before $\mathrm{LH}$ launcher powers up) and $385^{\circ} \mathrm{C}$ (when $\mathrm{LH}$ launcher powers off) respectively and the peak heat flux is located near FBG7. As function of the duration between two 
experiments (20 minutes in average), the initial temperature is spanning from $70^{\circ} \mathrm{C}$ (first pulse of the session) up to $300^{\circ} \mathrm{C}$ (during full plasma exploitation).

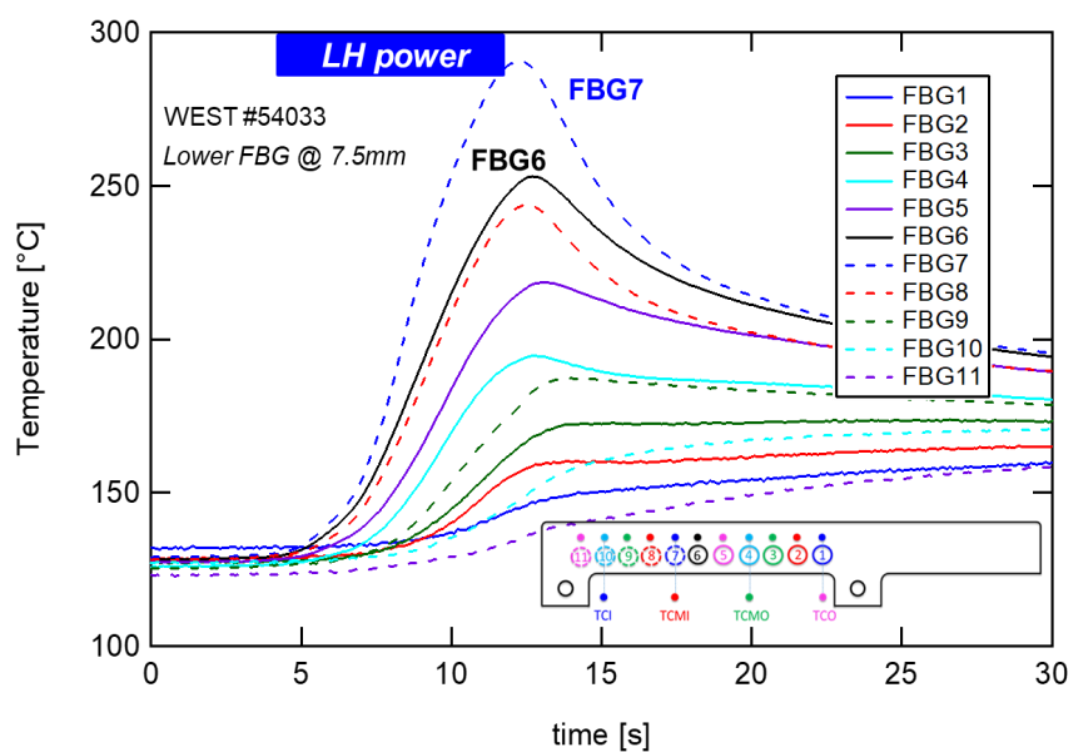

Figure 3: FBG temperature measurement during WEST experiment \#54033 $\left(\mathrm{I}_{\mathrm{p}}=500 \mathrm{kA}, \mathrm{P}^{\mathrm{LH}}=\right.$ 4.5 MW) showing the temperature rise and cooling of the tile during and after the power cut-off respectively.

\section{4) FBG temperature data-base}

The maximum of temperature reported by one upper FBG probes after each pulse during the C3 (blue points) and C4 (red points) experimental campaigns are displayed in figure 4. During $\mathrm{C} 3$, the temperature is covering the small to medium temperature range, from $70^{\circ} \mathrm{C}$ up to $400^{\circ} \mathrm{C}$. In this temperature range, conventional $\mathrm{FBG}$ measurement (without regeneration) should have worked. During $\mathrm{C} 4$, the progress made in WEST in terms of injected power and time duration leads to high temperature in the divertor, up to $830^{\circ} \mathrm{C}$ (pulse with $90 \mathrm{MJ}$ cumulated injected energy, \#55070), which is close to specification used for the FBG design. 


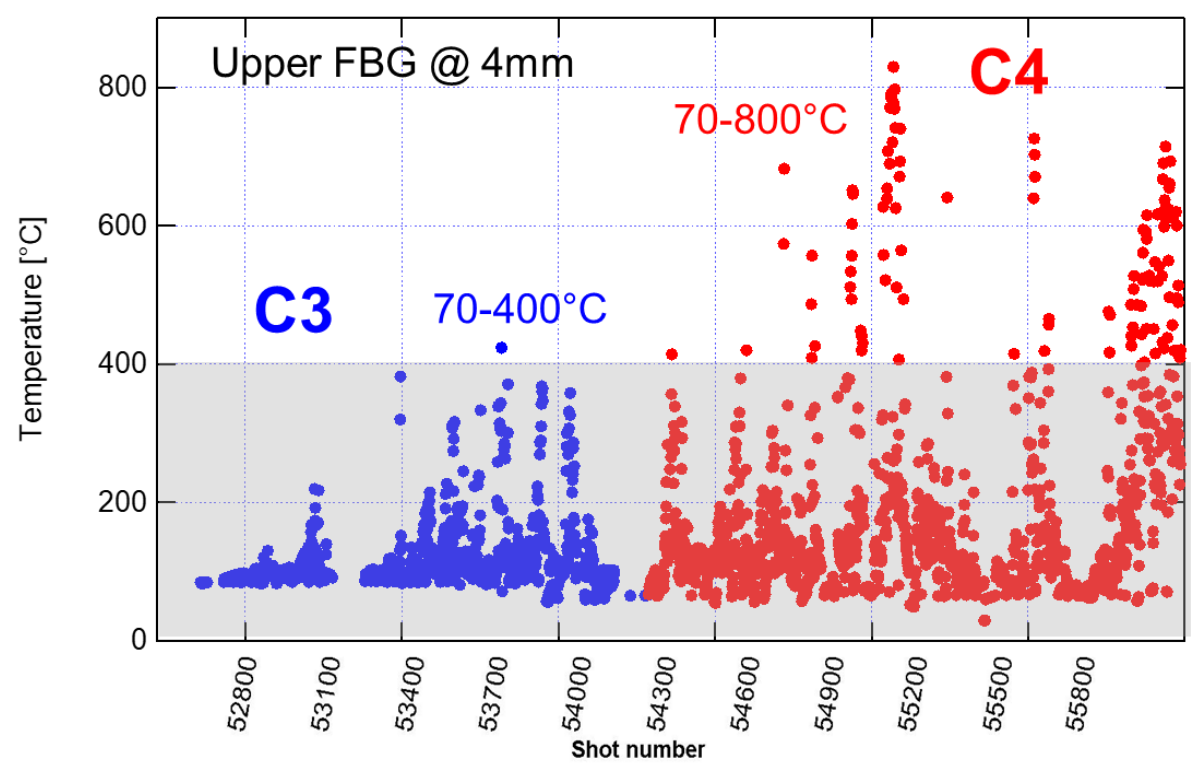

Figure 4: maximum temperature per pulse reported during C3 and C4 experimental campaigns.

Using the FBG temperature measurements, we have been able to derive the heat flux and temperature distribution at the top surface [17]. So far, the maximum peak heat flux computed from the FBG database is $\sim 5 \mathrm{MW} \cdot \mathrm{m}^{-2}$ on the OSP (high power experiment \#54719). The maximum surface temperature computed from the same database is about $1000{ }^{\circ} \mathrm{C}$ (pulse with $90 \mathrm{MJ}$ cumulated injected energy, \#55070) thus below the technological limit of $1200^{\circ} \mathrm{C}$ to avoid any degradation of the $\mathrm{W}$-coating (recrystallization, cracks and delamination). About 110 pulses experienced high temperature, typically $>400^{\circ} \mathrm{C}$, where conventional FBG system would failed and potentially not recover because of the erasure of the gratings. Regenerated FBG reached the high temperature domain and the 44 FBG gratings installed in WEST still survive (4 FBG probes, 11 gratings each) at the end of the campaigns. 


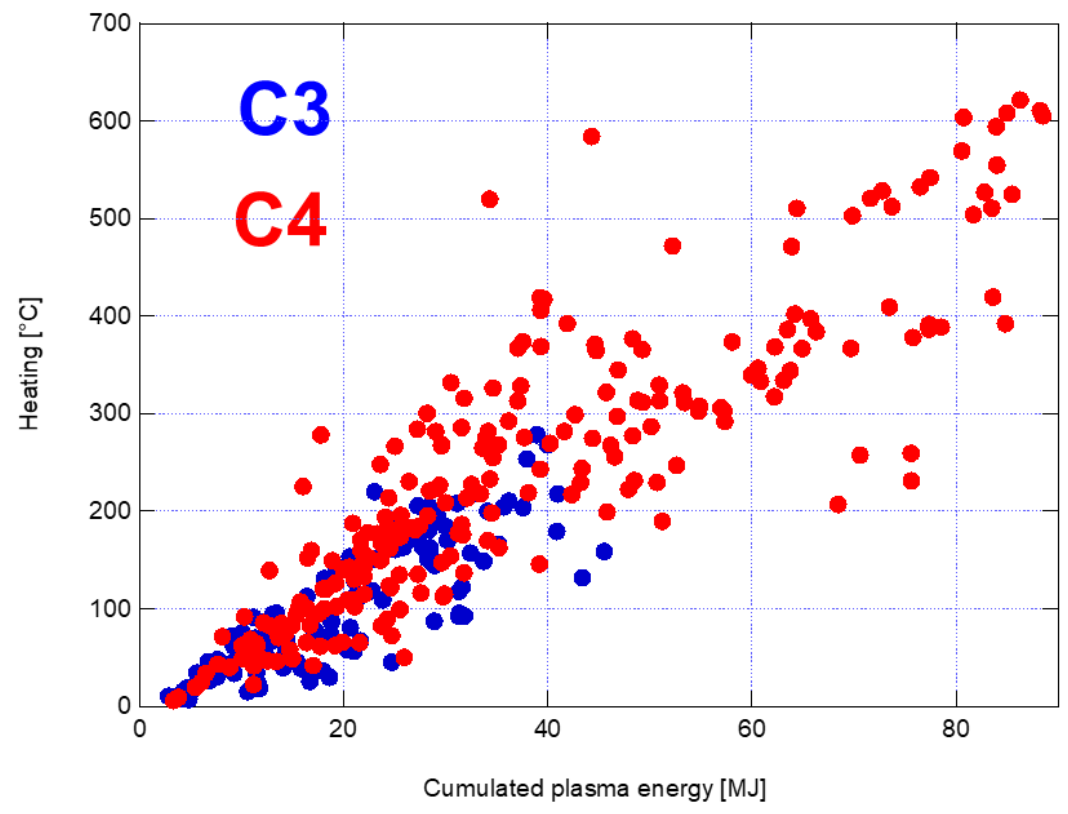

Figure 5: Temperature rise of the divertor PFU as function of the cumulated plasma energy during the overall plasma experiments ( $\mathrm{C} 3$ and $\mathrm{C} 4$ experimental campaigns).

The absolute temperature achieved at the end of the pulse, is the combination of the accumulated energy through previous experiments and the heating of the divertor PFUs due to plasma heat load. To evaluate the progress achieved in WEST in term of energy accumulated in the divertor during one pulse, it is useful to subtract the initial temperature and look at the temperature rise during the overall plasma experiments $\Delta T=\left(T_{\max }-T_{0}\right)$, this is plotted as function of the cumulated plasma energy in figure 5. During C3 experimental campaign the maximum temperature rise was $300^{\circ} \mathrm{C}$ with about $40 \mathrm{MJ}$ injected energy while it reaches $600^{\circ} \mathrm{C}$ with $90 \mathrm{MJ}$ injected energy (\#55070) during $\mathrm{C} 4$. The large data scattering is explained by the experimental scenario which is varying from pulse to pulse: magnetic equilibrium (upper or lower single null, far or close X-point), machine conditioning (cleaning discharge, boronization), heating power settings (ICRH, LHCD, position and edge density), plasma radiation and fueling.

\section{Dynamic of the spectrum under high temperature measurements}

The highest temperature measured with $\mathrm{FBG}$ system is $830^{\circ} \mathrm{C}$. The experiment has been specifically designed to expose pre-damaged monoblocks to significant plasma duration and heat load. Figure 6 displays the temperature time traces recorded during this experiment for each of the eleven FBGs. The main plasma parameters are kept constant for about 20s duration: injected power $\mathrm{P}_{\text {inj }}=4.5 \mathrm{MW}$, plasma current $\mathrm{I}_{\mathrm{p}}=500 \mathrm{kA}$, the line-averaged density $\bar{n}_{e} \sim 4 \times 10^{19} \mathrm{~m}^{-2}$. The magnetic field is $\mathrm{B}_{\mathrm{T}}=3.7 \mathrm{~T}$ and the $\mathrm{X}$-point is $75 \mathrm{~mm}$ above the target (far X-point magnetic configurations). The outer strike point (OSP) is located between FBG\#9 and FBG\#8, more likely near FBG\#8 
exhibiting the highest temperature. FBG\#9 is located in the private flux region (toward high field side) and FBG\#7 is located in the Scrape-Off Layer (SOL) region (toward low field side). The cumulated injected energy is $90 \mathrm{MJ}$, which is one of the most energetic experiment performed in WEST with the lower single null magnetic configuration so far (150 MJ has been obtained in upper single null configuration running with a fully actively cooled divertor and no FBG system). The initial temperature of the $\mathrm{W}$-coated PFU (on the lower divertor) was about $210^{\circ} \mathrm{C}$ and final temperature is about $830^{\circ} \mathrm{C}$. The heat flux computed with the 2D CGM method [17] using the FBG measurements is about $3.5 \mathrm{MW} \cdot \mathrm{m}^{-2}$ on the top surface of the component and the heat flux decay length measured on the target is $\lambda_{q}=20 \mathrm{~mm}$. The surface temperature computed for this pulse is $1000^{\circ} \mathrm{C}$, which is below the temperature limit to avoid tungsten recrystallization.

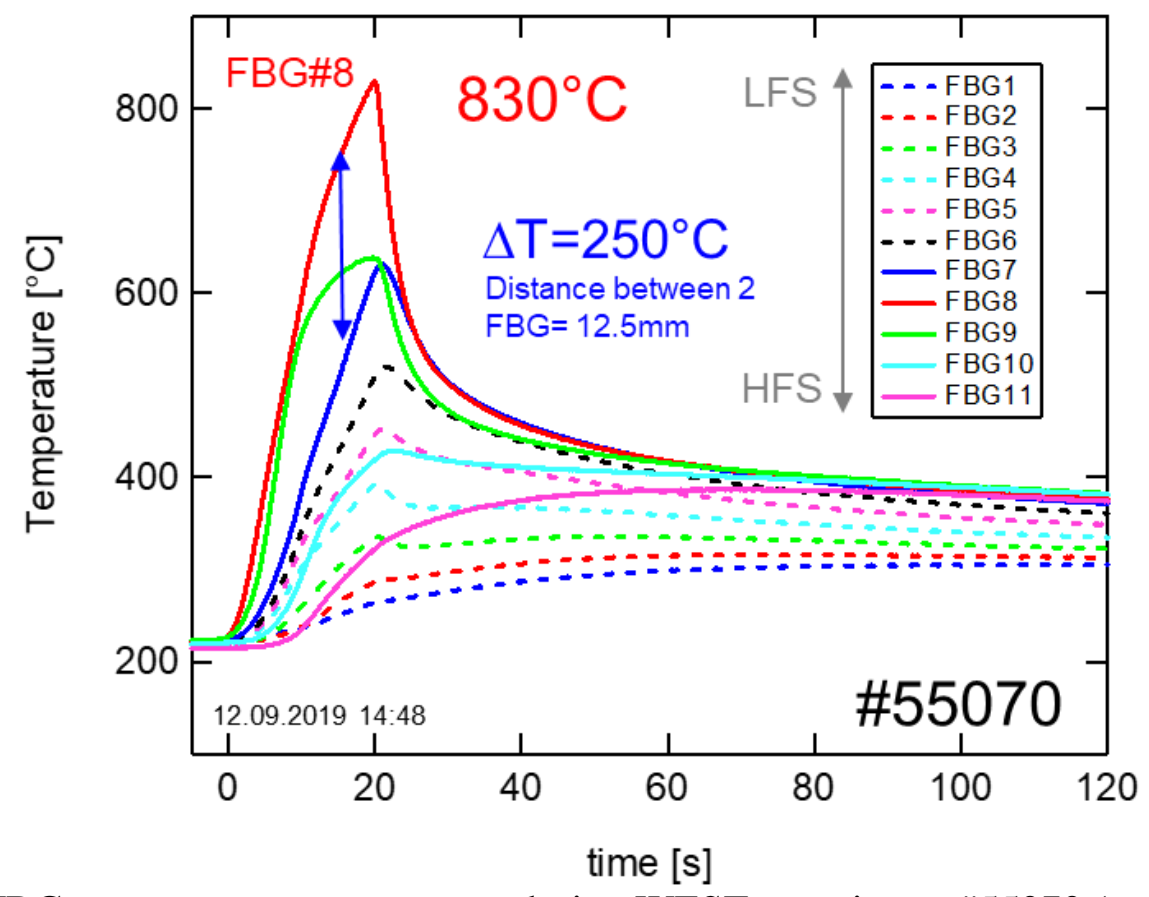

Figure 6: FBG temperature measurement during WEST experiment \#55070 (upper FBG probe located $4 \mathrm{~mm}$ below the surface).

Another important technological issue for FBG temperature measurement is the presence of temperature gradient on the scale of the grating. For the experiment depicted above, the temperature difference between FBG\#8 and FBG\#7 is about $250^{\circ} \mathrm{C}$. The space between two FBG being $12.5 \mathrm{~mm}$, we can estimate the average temperature gradient: $\left\langle\frac{\Delta T}{\Delta x}\right\rangle=20^{\circ} \mathrm{C} / \mathrm{mm}$. The size of the FBG being $3 \mathrm{~mm}$, this means we have about $60{ }^{\circ} \mathrm{C}$ temperature gradient along the grating. Consequently, the grating period $\Lambda$ (equation 1 ) can vary spatially giving rise to peak broadening and collapsing. The dynamic of the peak collapsing due to temperature gradients is illustrated in figure 7 . During 
the first couple of seconds, the peak is shifted due to temperature rise in the component. Then, after $6 \mathrm{~s}$, the peak amplitude starts to decrease and becomes broader because of the multi-resonance occurring in the grating due to the temperature gradient: the temperature gradients induce a chirp of the grating pitch along its length. After power cut-off and plasma current ramp down occurring at 20s, the temperature drops and the Bragg peak is rapidly recovered because the heat diffuses along the component and the strong temperature gradient is removed in less than $2 \mathrm{~s}$. Despite the collapsing process, the position of the peak was properly detected allowing the temperature measurement. The hard limit for temperature measurement would be the full collapsing of the Bragg peak, which could appear under higher temperature gradients.

(a) heating phase

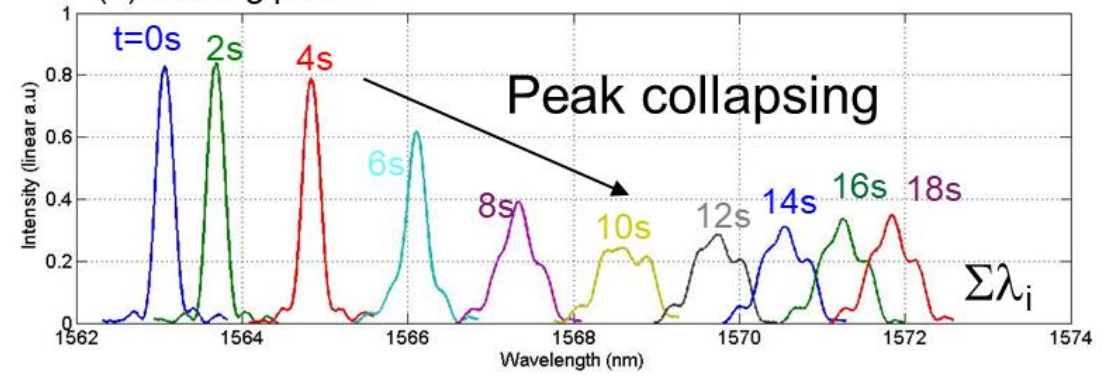

(b) cooling phase

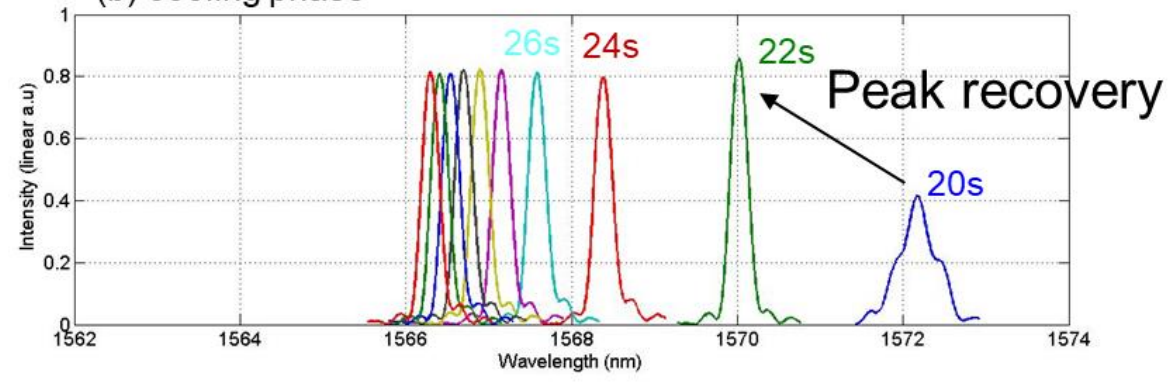

Figure 7: Spectrum of the Bragg peak FBG\#8 at different time step (\#55070). During heating phase (a) exhibiting peak collapsing due to $\mathrm{T}^{\circ}$ gradient and followed by cooling phase (b) with peak recovery.

\section{Ageing of the FBG diagnostic}

One of the main issue with FBG measurement is the irreversible erasure of the grating under high temperature. Regenerated FBGs is an efficient approach to get temperature-stable gratings up to $900^{\circ} \mathrm{C}$ during thousands of hours and even beyond in temperature over limited timescale. Even if the heat load is not continuously applied to the instrumented PFUs (as depicted in section 2), the FBG-based sensing lines must stay operational without any maintenance or replacement during 
several years. The use of FBG in WEST tokamak represents a unique feedback on long-term use of FBG under extreme condition (high heat load, fast temperature rise, strong temperature gradient, intense magnetic field, vacuum condition and presence of neutrons from fusion reaction). Regarding the fusion reactions (mainly between deuterium nucleus in the WEST device), cumulated neutron measurements gives about $3.5 \times 10^{15}$ neutrons during the full period of operation in the overall device. The FBG probes are located at $0.7 \mathrm{~m}$ from the plasma center and major radius is $\mathrm{R}_{0}=2.5 \mathrm{~m}$ (see figure 1). At this position, the neutron fluency is therefore about $1,5 \times 10^{10} \mathrm{n} / \mathrm{cm}^{2}$, which is actually too small to produce any damage on the fiber as shown in [19]. As seen in section 2 , the system was working successfully during more than 3 years in the WEST tokamak. To investigate the ageing of the system, we propose first to compare the FBG spectrum before WEST operation and after removal of the diagnostic from WEST (see figure 8). We can first observe that the baseline has decreased by about $2 \mathrm{~dB}$ while the peak amplitude remains constant $\sim 10 \mathrm{~dB}$ after three years of operation. The decrease of the baseline could be attributed to potential changes in reflection inside the fiber. However, the baseline is eliminated in the data processing (peak detection algorithm), therefore this has no incidence on the peak detection. Most importantly, the peak amplitude is the main indicator of the quality of the grating. Since we do not observe variation of the peak amplitude, we can conclude that the refractive index modulation corresponding to the FBG does not suffer any degradation.

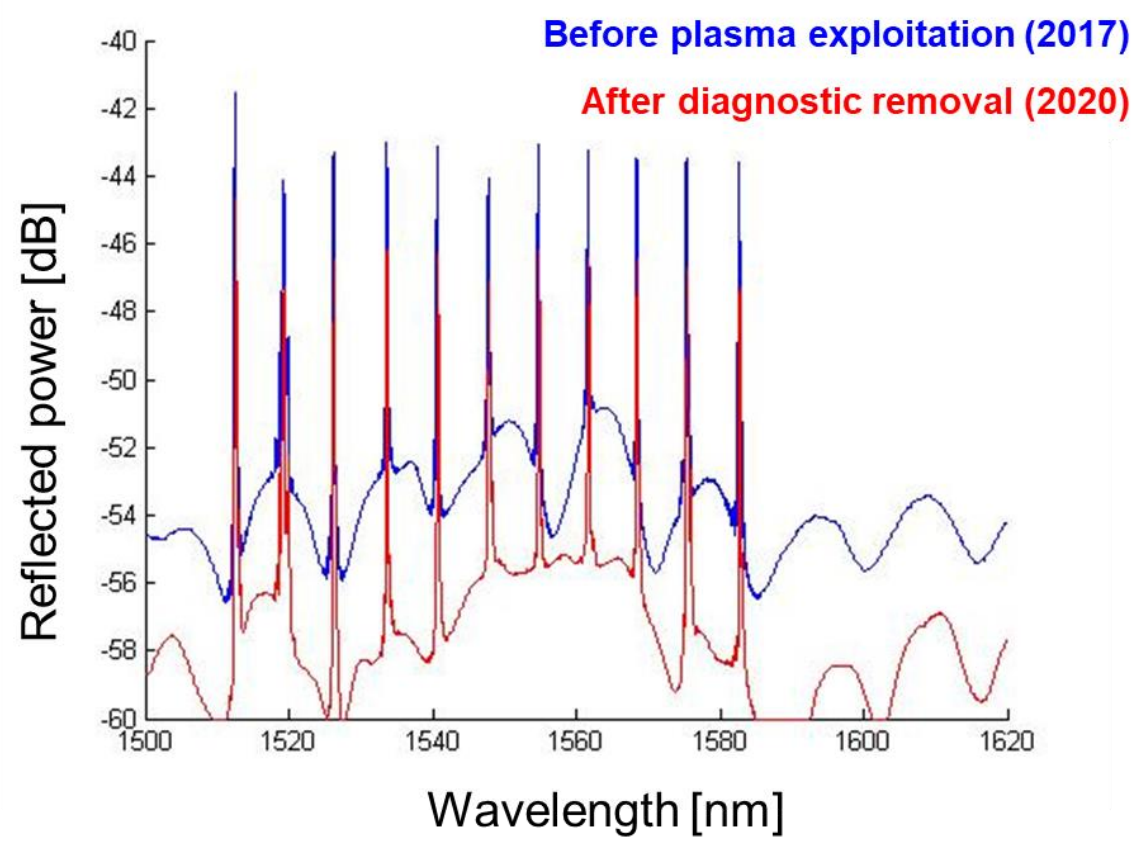

Figure 8: WEST FBG spectrum before plasma exploitation (blue) and after diagnostic removal (red) recorded at room temperature. 
To complete this first observation, we have compared the temperature measurements provided by the FBG system with the thermocouple diagnostic, a well-established and robust system. The integration of the TC in the machine is almost identical to the FBG system. The TC and FBG are physically located in different port-plugs with exactly the same location (in the maximum heat flux region for the OSP) regarding the toroidal ripple modulation $\left(30^{\circ}\right.$ toroidal symmetry). The integration in the component is slightly different, as shown in figure 9. To minimize the cabling in the divertor, we are limited to four TCs embedded in a single component. The distance between two TC is $37.5 \mathrm{~mm}$, three time larger than the distance between two consecutive FBGs (12.5 mm). The TCs are inserted in $1 \mathrm{~mm}$ diameter hole directly inside the component while FBG probes are inserted in a lateral groove running out along the component. The position of the sensing points regarding the top surface are similar to the FBG system: TCs are located $7.5 \mathrm{~mm}$ below the surface. The temperature time trace measured with FBG (full lines) and TC (dashed lines) diagnostic are compared in figure 9 during WEST experiment specifically designed to get the outer strike point (OSP) well aligned with TC and FBG spot measurement (namely TCMI and FBG\#7) with the Xpoint located at $80 \mathrm{~mm}$ above the target. The plasma experiment has been performed at the end of the $\mathrm{C} 4$ experiment campaign, before the removal of the diagnostic. The pulse lasts for about $10 \mathrm{~s}$ duration, the injected power is $\mathrm{P}_{\mathrm{inj}}=4.5 \mathrm{MW}$ and plasma current is $\mathrm{I}_{\mathrm{p}}=500 \mathrm{kA}$. Before the pulses, the initial temperature are about $180 \pm 5^{\circ} \mathrm{C}$ for TC target and $167 \pm 7^{\circ} \mathrm{C}$ for FBG target, both targets being located in two different sectors at the same position regarding the toroidal modulation of the magnetic field (ripple effect). The temperature are supposed to be homogeneous in the components because the time duration between two plasma experiments is always longer than 15 minutes. The average difference between the two measurements is about $13{ }^{\circ} \mathrm{C}$, which is perfectly on-line with laboratory measurement performed before the installation of the system in the device. As shown in [3], FBG measurements have a systematic offset of $10^{\circ} \mathrm{C}$ compared to the TC. During the plasma experiment, the temperature rise are similar for FBGs and TCs. The dynamic is really different as function of the position of the sensor because of the heat flux distribution on the top surface, with the centimeter size heat flux decay length on the right side of the component (in the SOL region) and even shorter decay length in the left side of the component (in the private flux region). The overall dynamic is very well reproduced with both FBG and TC systems. After three years of operation, no particular drift in the temperature measurement is detected. 


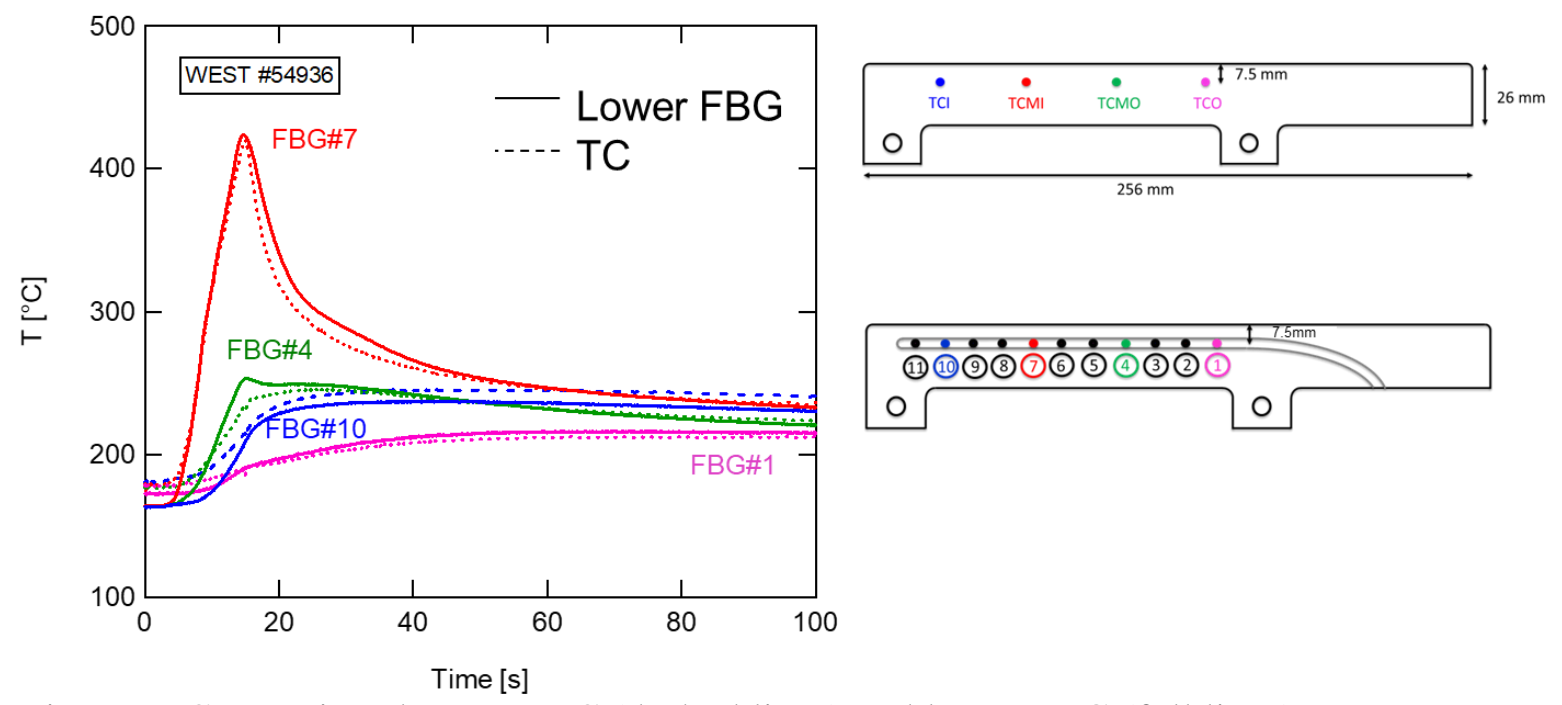

Figure 9: Comparison between TC (dashed lines) and lower FBG (full lines) measurements during pulse \#54936.

\section{Conclusion}

Regenerated FBGs preserve all the advantages of FBG-based metrology such as low intrusivity, immunity to electromagnetic field and multiplexing capabilities. The use of regenerated FBGs in WEST tokamak represents a unique feedback in fusion research device. The system was located in the most severe condition in the machine and has been routinely used during three years. It has survived to high heat load $\left(5 \mathrm{MW} \cdot \mathrm{m}^{-2}\right)$, numerous plasma experiments (2600), high temperature (up to $\left.830^{\circ} \mathrm{C}\right)$, fast temperature rise $\left(30^{\circ} / \mathrm{s}\right)$, strong temperature gradients $\left(20^{\circ} / \mathrm{mm}\right)$, intense magnetic field (3.7T), vacuum condition and noticeable gamma and neutron fluence from fusion reaction $\left(1,5.10^{10} \mathrm{n} / \mathrm{cm}^{-2}\right)$. The results presented in this paper demonstrate that FBG technology provides an accurate and reliable way to measure the temperature of plasma facing components. FBG measurement have been used all along this period to crosscheck the IR thermography measurements and characterize the plasma heat load [20]. Experimental outcomes are highly satisfactory and WEST has decided to install new FBG in the actively cooled components made of bulk tungsten monoblocs (ITER-like technology) as foreseen in the second phase of the WEST project [21]. In broader extent, FBG constitutes a promising sensing technology for measurements into severe environments such as those present in Fusion- and Fission-related nuclear applications.

Acknowledgments: This work has been carried out thanks to the support of the A*MIDEX project ( ${ }^{\circ}$ ANR-11-IDEX-0001-02) funded by the «Investissements d'Avenir » French Government program, managed by the French National Research Agency (ANR). The plasma experiments have been carried out within the framework of the EUROfusion Consortium and has received funding from the Euratom research and training program 2014-2018 and 2019-2020 under grant agreement 
No 633053. The views and opinions expressed herein do not necessarily reflect those of the European Commission or the ITER Organization.

\section{References:}

[1] J. Bucalossi et al., "The WEST project: Testing ITER divertor high heat flux component technology in a steady state tokamak environment," Fusion Engineering and Design, vol. 89, no. 7, pp. 907-912, Oct. 2014, doi: 10.1016/j.fusengdes.2014.01.062.

[2] M. Missirlian et al., "The WEST project: Current status of the ITER-like tungsten divertor," Fusion Engineering and Design, vol. 89, no. 7, pp. 1048-1053, Oct. 2014, doi: 10.1016/j.fusengdes.2014.01.050.

[3] Y. Corre et al., "Integration of fiber Bragg grating temperature sensors in plasma facing components of the WEST tokamak," Review of Scientific Instruments, vol. 89, no. 6, p. 063508, Jun. 2018, doi: 10.1063/1.5024514.

[4] K.O. Hill and G. Meltz. Journal of Lightwave Tehcnology, VOL. 15, NO. 8, August 1997

[5] A. Poncet, S. Brun, A. Foussat, R. Gallix, J. Knaster, F. Rodriguez-Mateos, and F. Simon IEEE TRANSACTIONS ON APPLIED SUPERCONDUCTIVITY, VOL. 22, NO. 3, JUNE 20129500604

[6] A. Li Puma, G. Aiello, F. Gabriel, G. Laffont, G. Rampal and J.-F. Salavy. Fusion Engineering and Design. 85 (2010) $1642-1652$

[7] K. Ioki, A. Bayon, C.H. Choi, E. Daly, S. Dani, J. Davis, B. Giraud,Y. Gribov, C. HamlynHarris, C. Jun, B. Levesy, B.C. Kim,E. Kuzmin, R. Le Barbier, J.-M. Martinez, H. Pathak,J. Preble, J.W. Sa, A. Terasawa, Yu. Utin, X. Wang. Fusion Engineering and Design 88 (2013) 590- 596 [8] C. Lescure, S. Hotchin, E. Ivings, M.F. Johnson, V. Riccard, M. Walsh, A. West. Fusion Engineering, 2009. SOFE2009. $23^{\text {rd }}$ IEEE Symposium. DOI: 10.1109/FUSION.2009.5226470

[9] C. Vorpahl, W. Suttrop, M. Ebner, B. Streibl, H. Zohm, the ASDEX Upgrade TeamMax. Fusion Engineering and Design 88 (2013) 537- 540

[10] Fibre Bragg grating sensors for fusion diagnostics: Temperature monitoring of a tungsten mono-block mock-up under high heat flux, Fusion Engineering and Design, 150(2020)111378. https://doi.org/10.1016/j.fusengdes.2019.111378

[11] Multi-parameters measurement of EAST PFCs prototype with FBG sensors, Fusion Engineering and Design, 122(2017)1-7. https://doi.org/10.1016/j.fusengdes.2017.10.005

[12] G. Laffont, R. Cotillard and P. Ferdinand. Meas. Sci. Technol. 24 (2013) 094010 (5pp)

[13] M. Firdaouss, Y. Corre, P. Languille, H. Greuner, E. Autissier, C. Desgranges, D. Guilhem, J.P. Gunn, M. Lipa, M. Missirlian, J.-Y. Pascal, C. Pocheau, M. Richou and E. Tsitrone. Phys. Scr. T167 (2016) 014012 doi:10.1088/0031-8949/2016/T167/014012

[14] M.-H. Aumeunier, M. Kocan, R. Reichle and E. Gauthier. "Impact of reflections on the divertor and first wall temperature measurements from the ITER infrared imaging system". Nuclear Materials and Energy 000 (2017) 1-5. https://doi.org/10.1016/j.nme.2017.02.014 
[15] J. Gaspar, Y. Corre, J-L. Gardarein, M. Firdaouss, D. Guilhem, M. Houry, G. Laffont, C. Le Niliot, M. Missirlian, C. Pocheau and F. Rigollet. "Surface heat flux estimation with embedded fiber Bragg gratings measurements: Numerical study". Nuclear Materials and Energy. 000 (2016) 1-5. https://doi.org/10.1016/j.nme.2016.10.015

[16] G. Laffont, R. Cotillard, N. Roussel, Y. Corre, J. Gaspar, and C. Pocheau. "Thermal monitoring of W-coated graphite components facing the West Tokamak plasma with arrays of regenerated FBGs". 26th International Conference on Optical Fiber Sensors OSA Technical Digest (Optical Society of America, 2018), paper ThE95 https://doi.org/10.1364/OFS.2018.ThE95

[17] J. Gaspar et al., "First heat flux estimation in the lower divertor of WEST with embedded thermal measurements," Fusion Engineering and Design, vol. 146, pp. 757-760, Sep. 2019, doi: 10.1016/j.fusengdes.2019.01.074.

[18] P, Moreau et al. "Measurements and controls implementation for WEST". Fusion Engineering and Design. Volume 123, November 2017, Pages 1029-103. https://doi.org/10.1016/i.fusengdes.2017.01.046

[19] A. Morana et al., "Irradiation Campaign in the EOLE Critical Facility of Fiber Optic Bragg Gratings Dedicated to the Online Temperature Measurement in Zero Power Research Reactors," in IEEE Transactions on Nuclear Science, vol. 63, no. 6, pp. 2887-2894, Dec. 2016, doi: 10.1109/TNS.2016.2618906

[20] N. Fedorzak, J. Gaspar, Y. Corre, A. Grosjean, X. Courtois, J.P. Gunn, R. Mitteau, R. Dejarnac, J. Bucalossi, E. Tsitrone, T. Loarer, S. Brezinsek, the WEST team. "Cross diagnostics measurements of heat load profiles on the lower tungsten divertor of WEST in L-mode experiments". 24 PSI conference (Korea)

[21] N. Chanet, Y. Corre, R. Cotillard, J. Gaspar, G. Laffont, C. Pocheau, G. Caulier, C. Dechelle, B. De Gentile, C. Destouches, F. Gallay, T. Gonzart, C. Hernandez, M. Missirlian, M. Richou, N. Roussel, B. Santraine and the WEST team. "Design and integration of femtosecond fiber Bragg gratings temperature probes inside actively cooled ITER-like plasma-facing components". This conference. 